\title{
QUALIDADE DE VIDA NA INFÂNCIA: HÁBITOS SAUDÁVEIS E O LÚDICO.
}

Rafael José Espindola, Alan Alves Rocha, José Milton de Lima, Marcia Regina Canhoto de Lima, Cristiane Maria Zambelli, Janaína Bolssone do Prado, Joyce Cristina Claro Menoti, Paulo Sérgio de Lima.

Departamento de Educação Física, Faculdade de Ciências e Tecnologia. UNESP - Presidente Prudente. E-mail: rafael espindola92@homail.com

\section{RESUMO}

O presente trabalho retrata resultados de uma pesquisa que tem como foco principal a ludicidade como meio para a melhoria da qualidade de vida na infância. Considera que problemas relacionados à saúde são determinados em larga escala pelos hábitos e modos de vida. A metodologia de natureza qualitativa caracteriza-se como pesquisa-ação. O referencial teórico apoia-se em autores da Educação Física e documentos oficiais divulgados pelo Ministério da saúde e IBGE. Inicialmente, foi elaborado um diagnóstico no qual foram realizadas avaliações antropométricas das crianças da escola parceira. A partir dos dados, verificou-se a composição corporal das crianças, constando que em cada três crianças, uma está acima do peso. Os resultados revelam a gravidade da situação e demonstram a necessidade de adoção de suportes teóricos que conscientizem toda a comunidade escolar e forneçam meios que garantam às crianças condições para vivências da atividade lúdica no interior e fora da escola.

Palavras-chave: Infância; Ludicidade; Obesidade; Educação, Ensino Fundamental.

\section{INTRODUÇÃO}

O projeto "Multiplicando Saberes: Ludicidade e Qualidade de Vida na Infância" articula-se ao subprojeto intitulado "A Formação de Professores de Educação Física para as Series Iniciais do Ensino Fundamental a Partir da Valorização da Infância e da Cultural Corporal de Movimento" (PIBID), da Faculdade de Ciências e Tecnologia de Presidente Prudente FCT/UNESP. Conta ainda com a cooperação do Centro de Estudo e Laboratório de Avaliação e Prescrição de Atividades Motoras (CELAPAM), departamento este também integrante da mesma instituição.

Parte do pressuposto de que a ludicidade representa um recurso privilegiado da Educação Física contemporânea na busca da aquisição, por parte dos alunos dos anos iniciais do ensino fundamental, de hábitos voltados à saúde e a melhoria da qualidade de vida.

Para uma melhor compreensão de como se efetiva este projeto, julgamos necessário, primeiro apresentar o Subprojeto: “A Formação de Professores de Educação Física para as Series Iniciais do Ensino Fundamental a Partir da Valorização da Infância e da Cultura Corporal do Movimento", que faz parte do Programa Institucional de Bolsa de Iniciação à Docência (PIBID), desenvolvido na Faculdade de Ciências e Tecnologia - FCT/UNESP, Campus de Presidente Prudente, em parceria 
com a Escola Padre Emílio Becker da rede de ensino do município de Presidente Prudente. Adota como objetivo central, aprimorar o conhecimento teórico e prático na formação inicial, de Alunos Bolsistas do Curso de Licenciatura em Educação Física e continuada dos profissionais da escola parceira.

Para a cultura corporal de movimento ser vivenciada pelos alunos faz-se necessário a mediação dessa temática e, a partir daí incorporação de concepções e práticas relacionadas ao tema em suas rotinas. Ainda, se essa cultura for apresentada às crianças num caráter lúdico, possibilita relações positivas com a atividade física, por ser um meio que promove possibilidades de livre escolha por parte daqueles que participam. Tal estratégia pode tornar a pratica corporal como uma experiência mais flexível e participativa e oportunizar uma maior proximidade entre a criança e a cultura corporal.

Neste aspecto, este projeto se justifica, pois no primeiro momento ele contribuirá para que educadores dos âmbitos familiar e escolar exercer o seu papel no processo de formação integral das crianças, de modo a refletir na melhoria da qualidade de vida.

\section{OBJETIVOS}

- Colaborar na multiplicação de conhecimentos sobre os benefícios que as atividades lúdicas podem promover nas crianças.

- Favorecer a reflexão sobre a melhoria da qualidade de vida e o fortalecimento do potencial de saúde das crianças na perspectiva da ludicidade.

- Proporcionar conhecimentos aos pais das crianças sobre a importância das atividades lúdicas e como se tornar importantes aliados no combate ao sedentarismo infantil.

\section{FUNDAMENTAÇÃO TEÓRICA}

Miranda (2006) explana que os estudos relacionados à atividade física para a promoção da saúde estão intimamente relacionados ao papel da escola na sociedade e, em especial, da Educação Física escolar como área de conhecimento que trata das atividades corporais e de movimento. As crianças muitas vezes só tem a escola, como ambiente para sua prática corporal, podendo assim contribuir para contemplar a função de colaboradora ao combate do sedentarismo infantil.

Quando tratamos de saúde dentro do ambiente escolar, e especificamente no Ensino Fundamental, não devemos ter a visão da aquisição de hábitos saudáveis a partir de programas 
reduzidos somente a medidas impostas, mas na busca da conscientização do educando a respeito de seus hábitos.

Segundo Guedes (1999, p.11) “[...] a saúde é educável e, portanto, deve ser tratada não apenas com base em referenciais de natureza biológica e higienista, mas, sobretudo em um contexto didático-pedagógico". O hábito se constrói a partir da educação e da conscientização.

Melo e colaboradores (2004) afirmam que a obesidade infantil aumenta em todas as camadas sociais brasileiras e, ainda, que a prevenção pode reduzir o número de doenças crônicas degenerativas. Por sua vez, Alves (2003) ressalta que ser fisicamente ativo desde a infância é um fator que pode gerar muitos benefícios, não só na área física e no controle das doenças crônicas da vida adulta, mas também nas esferas social e emocional.

Desta forma, torna-se relevante e necessário pesquisar e incentivar a utilização do lúdico para a aquisição de conhecimentos a respeito do corpo, de suas potencialidades e especialmente na sua manutenção saudável. Infelizmente a pratica corporal, pautada em perspectiva lúdica, vem ocupando posição secundária nas escolas, que focam somente a preparação para o trabalho e para o futuro. Pesquisa realizada por Lima (2008) com alunos pré-escolares constatou que, mesmo nesta modalidade educacional, a brincadeira está cada vez mais secundarizada e substituída por "lições" e tarefas. Até mesmo para as crianças as atividades lúdicas estão sendo negadas.

O brincar na infância deve ser visto como atividade privilegiada e indispensável, considerando que a criança aprende sobre si mesma, sobre o mundo natural e social. O professor, nesta perspectiva, precisa enriquecer a sua prática pedagógica, complementando as atividades formais de ensino, com atividades lúdicas, favorecendo assim, entre outros aspectos, a aquisição de hábitos saudáveis, conhecimentos referentes à alimentação e à importância da adesão e vivência dos conteúdos relacionados à cultura corporal de movimento.

Atualmente, em meio ao processo de globalização, uma diversidade de produtos e tecnologias alcançam as crianças, junto a esses repercutem novos valores que em sua maioria consolidam o individualismo e outras mazelas de nossa sociedade capitalista, de uma forma especial a prática corporal acaba sendo enxergada de forma secundária na vida do jovem e da criança, já que outras possibilidades de entretenimento são vendidas como opções mais cômodas, seguras e modernas . Segundo Muller (2010), a criança que vive em cidades pequenas tem maior mobilidade corporal, em relação àquelas que vivem em metrópoles. Já Guedes \& Guedes (1998) defendem que as novas tecnologias afetam demasiadamente a qualidade de vida das pessoas. 


\section{METODOLOGIA}

$\mathrm{Na}$ busca de alcançar os objetivos propostos a pesquisa adotou a metodologia qualitativa, que utiliza de avalições, dados estatísticos, dialogando com a realidade.

Qualitativo está ligado aos sentidos produzidos nas relações sóciohistoricamente determinadas, afirmando a alteridade e as turbulências que nos movem a analisar, a dialogar, a buscar entender o que vivemos. As palavras mudam de significado em função dos sentidos que vão sendo agenciados nas práticas de acordo com as relações de força implicadas naquele momento (ROCHA, 2006, p.171).

Dessa forma, utiliza-se o procedimento do tipo pesquisa-ação que de acordo com THIOLLENT (2005, p.16) é um tipo de pesquisa social com base empírica concebida e realizada em estreita associação com uma ação ou com a resolução de um problema coletivo. Nesta modalidade de pesquisa pesquisadores e os participantes representativos da situação ou do problema estão envolvidos de modo cooperativo ou participativo.

A partir de reuniões de planejamento e avaliação, intervenções semanais na escola, aplicação de questionários, avaliações antropométricas os participantes investigam, aprendem e produzem sobre a temática. Ainda, em reuniões quinzenais no Grupo de pesquisa "Cultura Corporal: Saberes e fazeres", ampliam o suporte teórico metodológico e promovem discussões e reflexões sobre a infância e cultura em diversas perspectivas e contextos.

\section{RESULTADOS}

Com base nos tipos de medidas antropométricas realizadas entre os anos de 2011 e 2012 os resultados das avaliações mostraram um aumento na classificação de crianças obesas.

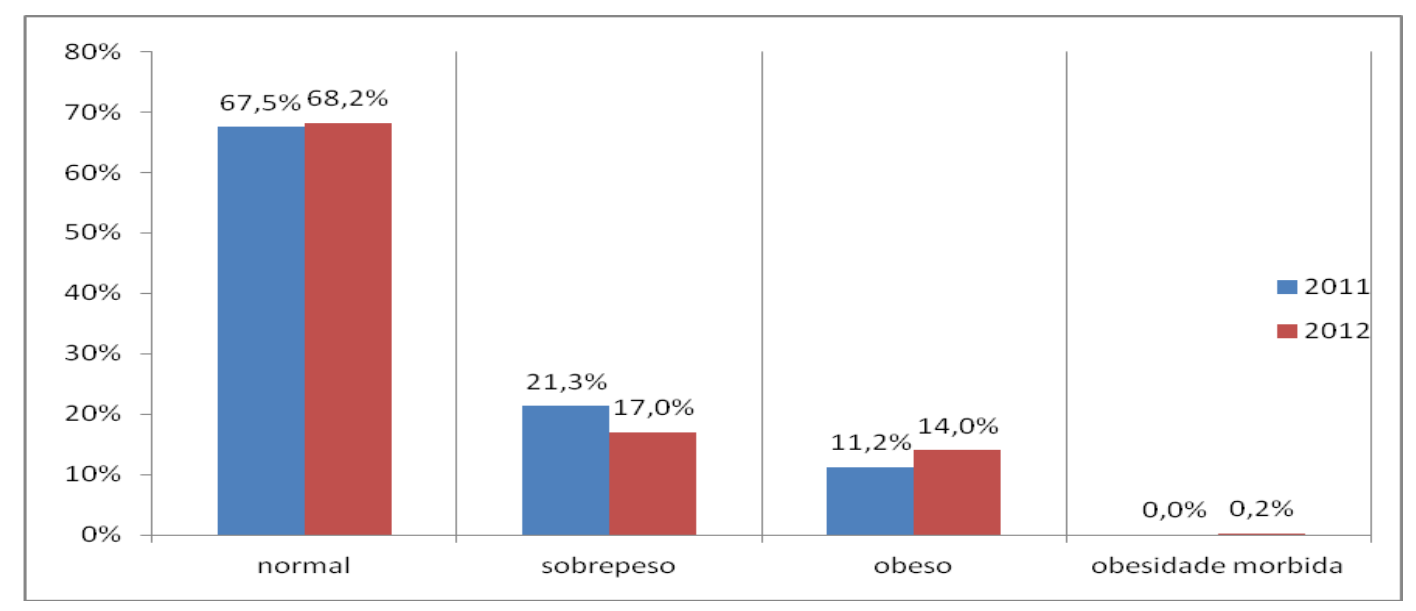


Na Figura 1, está apresentado o percentual geral do IMC dos alunos, no ano de 2011 e 2012, classificando-os em normal, sobrepeso, obeso e obesidade mórbida. Observa-se que os números de crianças indicadas com sobrepeso diminuíram, porém a taxa de obesidade aumentou. Um dado preocupante é o surgimento de crianças classificadas com obesidade mórbida.

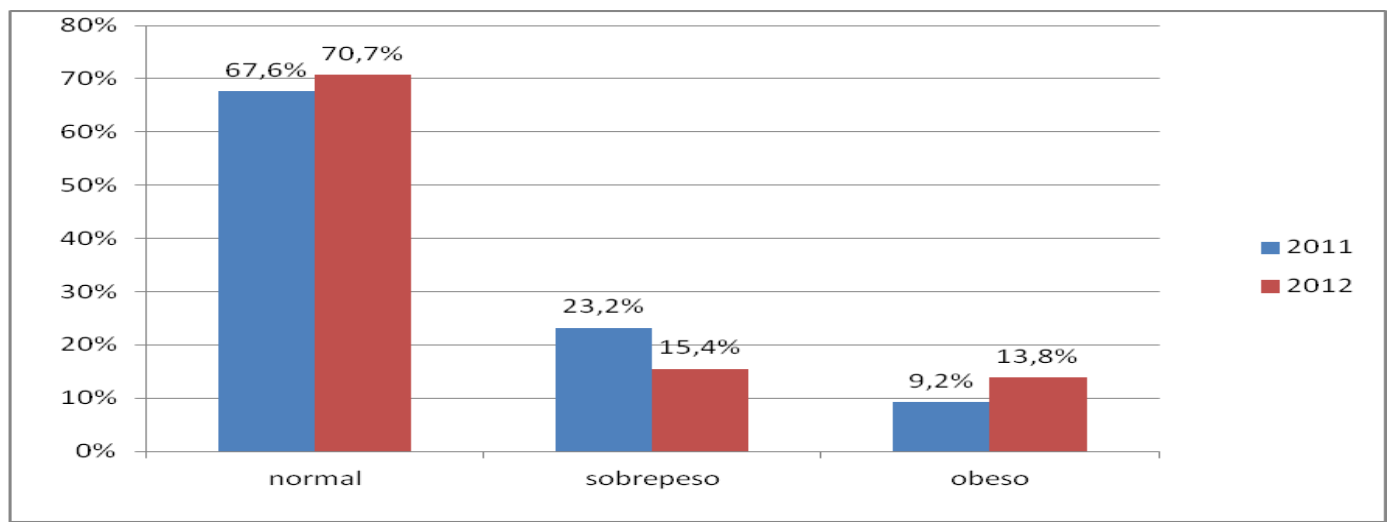

Na Figura 2, são apresentadas as comparações de IMC, no ano de 2011 e 2012, dos estudantes do gênero masculino, sendo classificado em normal, sobrepeso e obeso.

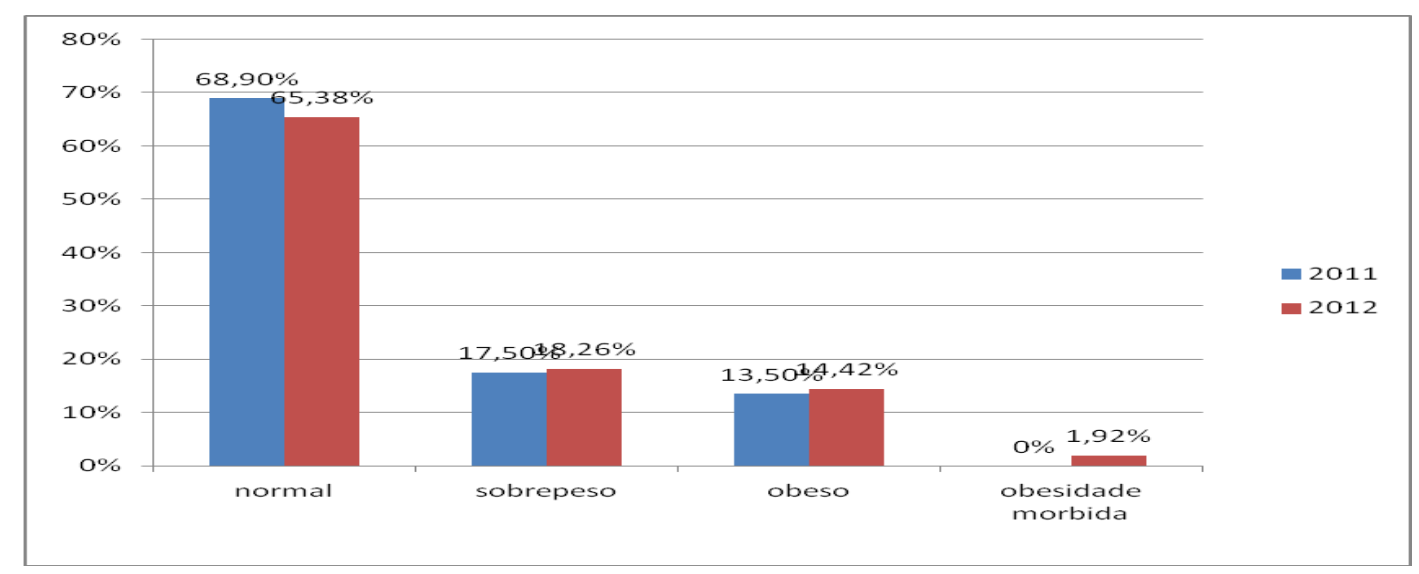

A Figura 3 apresenta a comparação do percentual de IMC nos dois anos de pesquisa, de jovens do gênero feminino, que tiveram 4 classificações: normal, sobrepeso, obeso e obesidade mórbida. Nota-se que os alunos do gênero feminino por não serem mais ativos do que os do gênero masculino tiveram aumento na porcentagem de sobrepeso e obeso, e houve casos de obesidade mórbida.

No presente estudo os dados coletados de 227 alunos mostraram quatro categorias: normal, sobrepeso, obeso e obesidade mórbida. Os alunos classificados com sobrepeso tiveram uma redução de 4,3\%, na classificação de obesidade um aumento de 2,8\% e do ano de 2011 para 2012 houve o surgimento de uma nova categoria, obesidade mórbida 0,2\%, dado este que nos mostra que a cada ano aumenta o número de obesidade infantil. 
A partir dos questionários aplicados nas crianças, durante o período da pesquisa, nota-se que 90\% das crianças não têm noção do que são hábitos saudáveis, quais os benefícios que uma brincadeira pode atribuir tanto para o seu aspecto motor, social e cognitivo. Nota-se também, que os meios de comunicações, principalmente a TV e os jogos eletrônicos têm sido motivos para a redução da prática corporal, considerando as possibilidades que oferecem de entretenimento.

A partir das intervenções, durante um período de dois anos, ficou constatado que houve uma ampliação da cultura lúdica das crianças, tanto no ambiente escolar, quanto no ambiente família, segundo depoimentos das próprias crianças, pais e professores.

\section{DISCUSSÕES}

O número de crianças obesas e com sobrepeso pesquisadas é preocupante, se faz necessária no contexto escolar e familiar ações que incentivem a reversão deste quadro, favorecendo a reflexão à respeito da qualidade de vida, considerando o lúdico como uma ferramenta para essa melhoria. O projeto é uma das ações que têm contribuído para a conscientização sobre a qualidade de vida e seus benefícios de forma qualitativa e proporcionando vivências enriquecedoras do lúdico neste contexto. Deve-se ter em mente que esse processo é gradual e de longo prazo e necessita da colaboração de toda a comunidade envolvida, tanto escolar, quanto familiar.

\section{CONSIDERAÇÕES FINAIS}

Conforme destacamos, os pesquisadores revelam consenso em relação à hipocinesia e às doenças crônicas degenerativas diretamente relacionadas. Essa situação atualmente vem se alastrando e se encontra num estágio alarmante. Combater o sedentarismo torna-se, no contexto histórico atual, uma meta prioritária e a Educação Física é um componente curricular que pode muito contribuir para inverter essa situação, por meio de seus conteúdos conceituais e procedimentais.

O projeto a partir das atividades elaboradas procura desenvolver um resgate de hábitos que estão se perdendo ou são pouco estimulados na escola. As atividades físicas, vivenciadas de forma lúdica, têm um papel essencial para evidenciar uma vida mais ativa, alem de servir de estímulos para outras futuras atividades físicas que englobam a cultura corporal do movimento e principalmente favorece uma qualidade de vida melhor. 
A princípio, o projeto procura enfatizar junto aos seus colaboradores a incorporação por parte dos alunos da satisfação de praticar atividades físicas por meio de brincadeiras e jogos, num contexto lúdico, porém, sem ignorar a incumbência de desenvolver nos alunos uma percepção e consciência dos amplos sentidos que essas atividades podem proporcionar, para que comecem a internalizar noções do que ocorre no corpo e o quanto isso justifica a importância de serem fisicamente ativos.

De acordo com Guedes (1999, p.11) considerando que “[...] saúde é educável e, portanto, deve ser tratada não apenas com base em referenciais de natureza biológica e higienista, mas, sobretudo em um contexto didático-pedagógico".. O hábito se constrói a partir da educação.

O projeto tem constatado que a partir da afinidade, a opção de escolha por parte das crianças e a diversificação das brincadeiras e jogos, pautadas em um caráter lúdico, proporcionam oportunidades no interior da escola para o tratamento das temáticas: sedentarismo e qualidade de vida, trazendo repercussões que alcançam toda a comunidade escolar.

Temos também investido muito no processo de conscientização dos familiares e no aprofundamento desse tema para asseverar o entendimento dos educandos e educadores, visto como indispensáveis para mudanças que efetivamente repercutam na qualidade de vida das crianças.

\section{REFERÊNCIAS}

ALVES, J. G. B. Atividade física em criança: promovendo a saúde do adulto. Rev. Bras. Saude Mater. Infant. vol.3 no.1 Recife Jan./Mar. 2003.

AYRES, J. S.; SENA, S.S. A importância do lúdico na Educação Infantil: fundamentação teórica. Caderno Multidisciplinar de Pós - Graduação da UCP. Pitanga, n.1, v.1, p. 106-121, jan.2010.

BRASIL, Ministério da Saúde; Ministério da Educação. Programa Saúde na escola PSE, 2007. Disponível em < http://dab.saude.gov.br/portaldab/pse.php> Acesso em: 11 jun. 2013

DARTAGNAN, P. G. Educação para a Saúde Mediante Programas de Educação Física. São Paulo: revista motriz, v. 5, n. 1, p. 10-14, jun. 1999.

FREITAS JR. IF. Padronização de Técnicas Antropométricas, 1ำ ed. São Paulo: Cultura Acadêmica, 2009.

GUEDES, D.P. \& GUEDES, J.E.R.P. Crescimento, composição corporal e desempenho motor de crianças e adolescentes. São Paulo, CLR Baileiro, 1997.

LIMA, J. M. O jogo como recurso pedagógico no contexto educacional. São Paulo: Cultura Acadêmica: Universidade Estadual Paulista, Pró-Reitoria de Graduação, 2008. 
LIMA, J. M \& LIMA, M. R. C. Corpo e movimento: textos e contextos.-Marília, SP. Editora M3T Tecnologia e Educação, 2008.

MELLO, Elza D. de; LUFT, Vivian C. E MEYER, Flavia. Obesidade infantil: como podemos ser eficazes?. J. Pediatr. Rio de Janeiro, vol.80, n.3, p. 173-182, 2004.

MIRANDA, M. J. Educação Física e saúde na escola. Estudos. Goiânia, v.33, p. 643-653, jul/ago, 2006.

MULLER, F. (Org.) Infância em Perspectiva. São Paulo: Editora Cortez, 2010.

SALA de imprensa Antropometria e estado nutricional de crianças, adolescentes e adultos no Brasil. IBGE online, 2012. POF 2008-2009: desnutrição cai e peso das crianças brasileiras ultrapassa padrão internacional. Disponível em<:http://WWW.ibge.gov.br/home/presidência/noticias/noticia_visualiza.php?id_noticia=1699 \&id_pagina=1>. Acesso em: 24 mai. 2012.

ROCHA, M. L. Psicologia e as práticas institucionais: A pesquisa-intervenção em movimento. Porto Alegre: Psico, v. 37, n. 02, p. 169-174. 2006.

THIOLLENT, M. Metodologia da Pesquisa-ação. 14ạ edição. São Paulo: Editora Cortez, 2005. 